\title{
Quantitative hepatitis B surface antigen predicts the antiviral response and hepatocellular carcinoma development in patients with chronic hepatitis B
}

\author{
Sung Eun Kim
}

Department of Internal Medicine, Hallym University Sacred Heart

Hospital, Anyang, Korea

Received: June 14, 2017

Accepted: June 19, 2017

\section{Correspondence to}

Sung Eun Kim, M.D.

Department of Internal

Medicine, Hallym University

Sacred Heart Hospital, 22

Gwanpyeong-ro 17obeon-gil,

Dongan-gu, Anyang 14068,

Korea

Tel: +82-31-380-3705

Fax: +82-31-386-2269

E-mail: sekim@hallym.or.kr

\section{See Article on Page 636-646}

Chronic hepatitis B virus (HBV) infection is an important public health problem, worldwide, leading to liver-related complications such as chronic hepatitis, cirrhosis, and hepatocellular carcinoma (HCC) $[1,2]$. According to the antiviral therapy revolution against $\mathrm{HBV}$, the progression to cirrhosis and the development of HCC in patients with chronic HBV infection have been effectively suppressed if low HBV DNA loads are sustained $[3,4]$. However, the optimal timing and strategy of antiviral therapy for chronic HBV infection are somewhat difficult. With recent advances in molecular investigations, hepatitis $\mathrm{B}$ e antigen ( $\mathrm{HBeAg})$, serum alanine aminotransferase, HBV DNA, and HBV genotype, which are associated with the response to antiviral therapy, have been identified in patients with chronic hepatitis B (CHB) $[5,6]$. These biomarkers predict poor clinical outcomes in patients with $\mathrm{CHB}$ and help to individualize their antiviral therapy. Several studies have demonstrated that a lower baseline HBV DNA level predicts $\mathrm{HBeAg}$ loss or HBeAg seroconversion as well as viral suppression in patients with CHB receiving antiviral therapy [5]. Baseline and on-treatment response of HBV DNA level are well-established predictors of treatment outcomes in patients with $\mathrm{CHB}$ on antiviral therapy.

The hepatitis B surface antigen (HB$\mathrm{sAg}$ ) is an important biomarker of HBV infection and is qualitatively used to diagnose an HBV infection in the clinical setting. In the natural course of HBV infection, HBV DNA only originates from mature infectious particles and HBV DNA levels reflect viral replication. Because HBsAg can be derived from defective subviral particles, serum HBsAg levels reflect transcription of covalently closed circular DNA or mRNA translation and host immune control over HBV infection $[6,7]$. The combination of low serum HBsAg and serum HBV DNA levels can be used to predict inactive $\mathrm{HBV}$ carrier status and $\mathrm{HBsAg}$ loss after HBeAg seroconversion [8,9]. Levels of HBsAg have been reported to be a useful biomarker for evaluating viral replication and a predictor of treatment response in patients with $\mathrm{CHB}$ treated with interferon therapy [10]. Lee et al. [11] reported that a low HBsAg level is an important predictor of HBeAg loss in HBeAg-positive patients with CHB. These results indicate that measuring HBsAg levels may be a useful monitoring tool for CHB treatment during antiviral therapy.

In this issue, Cho et al. [12] reported 
that entecavir treatment over 5 years for patients with treatment-naïve CHB and genotype $\mathrm{C}$ shows an excellent virologic response rate and a low resistance rate. This retrospective study included 1,009 patients with CHB whose treatment was initiated with entecavir from 2007 through 2012. Among all patients, the cumulative biochemical response rates were $81.0 \%, 95.0 \%$, and $99.5 \%$ at 1,3 , and 5 years, respectively. The cumulative virologic response rates were $80.0 \%, 95.6 \%$, and $99.4 \%$ at 1,3 , and 5 years, respectively. Twelve patients (1.2\%) developed entecavir resistance. Interestingly, Cho et al. [12] measured HBsAg levels using stored available baseline serum samples of 271 patients $(126 \mathrm{HBeAg}$-negative and $145 \mathrm{HBeAg}$-positive patients). They revealed that lower HBsAg level (<5,000 IU/mL), lower HBV DNA level $\left(<6 \log _{10} \mathrm{IU} / \mathrm{mL}\right)$, and $\mathrm{HBeAg}$-negative status were independently associated with the virologic response. Patients with lower HBsAg levels had a significant higher virologic response and higher HBeAg seroclearance rates, particularly patients with a high viral load. Thus, patients with the combination of HBV DNA level $>6$ $\log _{10} \mathrm{IU} / \mathrm{mL}$ and HBsAg level > 5,000 IU/mL are at risk for a poor viral response. This study had several limitations: (1) retrospective design, and (2) a relatively small sample size to reveal the role of HBsAg level. However, this study showed long-term efficacy, the viral resistance of entecavir therapy in a real world setting, and demonstrated the factors associated with virologic response, including HBsAg level.

The association between serum HBsAg level and HCC has been elucidated in both the risk evaluation of viral load elevation and associated liver disease/cancer-hepatitis B virus (REVEAL-HBV) study and the Elucidation of Risk Factors for Disease Control or Advancement in Taiwanese Hepatitis B Carriers (ERADICATE-B) study. In the REVEAL-HBV study, serum HBsAg and HBV DNA levels were independent risk factors for HCC in HBV carriers. Serum HBsAg level was complementary to HBV DNA level in stratifying HCC risks, particularly in patients with a HBV DNA level < 200,000 IU/mL [13]. In the ERADICATE-B study, higher HBV DNA levels and serum HBsAg levels were positively correlated with the development of HCC in a dose-response manner in patients with HBV DNA levels > 2,000 IU/mL. This study also showed that serum HBsAg level $\geq 1,000 \mathrm{IU} /$ $\mathrm{mL}$ was an independent risk factor for HCC [14].
In brief, serum HBsAg level is an important biomarker for predicting virologic response and HCC development, in addition to serum HBV DNA level in patients with CHB. Furthermore, the combination of serum HBsAg level and serum HBV DNA level could be an ideal tool for predicting the treatment response and the development HCC.

\section{Conflict of interest}

No potential conflict of interest relevant to this article was reported.

\section{REFERENCES}

1. Liaw YF, Chu CM. Hepatitis B virus infection. Lancet 2009;373:582-592.

2. Chen DS. From hepatitis to hepatoma: lessons from type B viral hepatitis. Science 1993;262:369-370.

3. Chen CJ, Yang HI, Su J, et al. Risk of hepatocellular carcinoma across a biological gradient of serum hepatitis B virus DNA level. JAMA 2006;295:65-73.

4. Iloeje UH, Yang HI, Su J, et al. Predicting cirrhosis risk based on the level of circulating hepatitis B viral load. Gastroenterology 2006;130:678-686.

5. Lin CL, Kao JH. Hepatitis B viral factors and treatment responses in chronic hepatitis B. J Formos Med Assoc 2013;112:302-311.

6. Chan HL, Thompson A, Martinot-Peignoux M, et al. Hepatitis B surface antigen quantification: why and how to use it in 2011: a core group report. J Hepatol 2011;55:11211131.

7. Su TH, Hsu CS, Chen CL, et al. Serum hepatitis B surface antigen concentration correlates with HBV DNA level in patients with chronic hepatitis B. Antivir Ther 2010;15:1133-1139.

8. Brunetto MR, Oliveri F, Colombatto P, et al. Hepatitis B surface antigen serum levels help to distinguish active from inactive hepatitis B virus genotype D carriers. Gastroenterology 2010;139:483-490.

9. Tseng TC, Liu CJ, Su TH, et al. Serum hepatitis B surface antigen levels predict surface antigen loss in hepatitis B e antigen seroconverters. Gastroenterology 2011;141:517-525. e1-2.

10. Tangkijvanich $P$, Komolmit $P$, Mahachai V, Sa-nguanmoo P, Theamboonlers A, Poovorawan Y. Low pretreatment 
serum HBsAg level and viral mutations as predictors of response to PEG-interferon alpha-2b therapy in chronic hepatitis B. J Clin Virol 2009;46:117-123.

11. Lee MH, Lee DM, Kim SS, Cheong JY, Cho SW. Correlation of serum hepatitis B surface antigen level with response to entecavir in naive patients with chronic hepatitis B. J Med Virol 2011;83:1178-1186.

12. Cho JY, Sohn W, Sinn DH, et al. Long-term real-world entecavir therapy in treatment-naive hepatitis B patients: base-line hepatitis B virus DNA and hepatitis B surface antigen levels predict virologic response. Korean J Intern Med 2017;32:636-646.

13. Lee MH, Yang HI, Liu J, et al. Prediction models of longterm cirrhosis and hepatocellular carcinoma risk in chronic hepatitis B patients: risk scores integrating host and virus profiles. Hepatology 2013;58:546-554.

14. Tseng TC, Liu CJ, Yang HC, et al. High levels of hepatitis B surface antigen increase risk of hepatocellular carcinoma in patients with low HBV load. Gastroenterology 2012;142:1140-1149.e3. 